\title{
MCHM Acts as a Hydrotrope, Altering the Balance of Metals in Yeast
}

\author{
Amaury Pupo ${ }^{1} \varsigma$ Michael C. Ayers ${ }^{1} \varsigma$ Zachary N. Sherman ${ }^{1} \varsigma$ Rachel J. Vance ${ }^{1} \varsigma$ Jonathan R. Cumming ${ }^{1} \varsigma$ \\ Jennifer E. G. Gallagher ${ }^{1}$ (D)
}

Received: 19 June 2019 / Accepted: 24 July 2019 /Published online: 7 August 2019

(C) The Author(s) 2019

\begin{abstract}
While drugs and other industrial chemicals are routinely studied to assess risks, many widely used chemicals have not been thoroughly evaluated. One such chemical, 4-methylcyclohexane methanol (MCHM), is an industrial coal-cleaning chemical that contaminated the drinking water supply in Charleston, WV, USA in 2014. While a wide range of ailments was reported following the spill, little is known about the molecular effects of MCHM exposure. We used the yeast model to explore the impacts of MCHM on cellular function. Exposure to MCHM dramatically altered the yeast transcriptome and the balance of metals in yeast. Underlying genetic variation in the response to MCHM, transcriptomics and, mutant analysis uncovered the role of the metal transporters, Arn2 and Yke4, to MCHM response. Expression of Arn2, which is involved in iron uptake, was lower in MCHMtolerant yeast and loss of Arn2 further increased MCHM tolerance. Genetic variation within Yke4, an ER zinc transporter, also mediated response to MCHM, and loss of Yke4 decreased MCHM tolerance. The addition of zinc to MCHM-sensitive yeast rescued growth inhibition. In vitro assays demonstrated that MCHM acted as a hydrotrope and prevented protein interactions, while zinc induced the aggregation of proteins. We hypothesized that MCHM altered the structures of extracellular domains of proteins, and the addition of zinc stabilized the structure to maintain metal homeostasis in yeast exposed to MCHM.
\end{abstract}

Keywords Hydrotrope $\cdot$ MCHM $\cdot$ Zinc $\cdot$ Iron $\cdot$ Mitochondria $\cdot$ Zrt1 $\cdot$ Yke4 $\cdot$ Petite $\cdot$ Ionome $\cdot$ Yeast

\section{Background}

The potential for significant human exposure to toxic substances is increasing as thousands of chemicals in routine use have had little safety testing [1-3]. 4-Methylcyclohexane methanol (MCHM) is alicyclic primary alcohol used as a cleaning agent in the coal industry. Although health and safety information for this compound is limited, its widespread use in the coal-producing regions of the USA represents a potential hazard to humans and ecosystems. In January 2014, a large quantity of MCHM was spilled into the Elk River in West Virginia, USA and contaminated the drinking water supply of 300,000 people, exposing them to unknown health risks [4].

Amaury Pupo and Michael C. Ayers are Co-first authors

Electronic supplementary material The online version of this article (https://doi.org/10.1007/s12011-019-01850-z) contains supplementary material, which is available to authorized users.

Jennifer E. G. Gallagher

jegallagher@mail.wvu.edu

1 Department of Biology, West Virginia University, 53 Campus Drive, Life Sciences Building Rm 5105, Morgantown, WV 26506, USA
People exposed to MCHM through the contaminated drinking water reported a variety of significant ill effects [5].

MCHM is not easily degraded biologically because of its low reactivity [6]. In contrast to other well-studied hydrocarbons, such as cyclohexane and benzene, the effects of MCHM on metabolism are under studied [7]. Yeast strains exposed to MCHM exhibited increased expression of proteins associated with the membrane, cell wall, and cell structure functions, while MCHM metabolites mainly induced proteins related to antioxidant activity and oxidoreductase activity [3]. With human A549 cells, MCHM mainly induced DNA damage-related biomarkers, which indicates that MCHM is related to genotoxicity due to its DNA damage effect on human cells [3].

Yeast provides an ideal model system to understand the interplay between metabolic pathways involved in the transport, toxicity, and detoxification of MCHM. Further, the use of yeast strains with mutations in various metabolic pathways allows direct evaluation of targeted pathways on the fate and toxicity of MCHM in cells. "Petite yeast," strains with mutations that disrupt the electron transport chain that produces ATP in the mitochondria, grow more slowly and have smaller cell size than "grande yeast" (wild type). Because these yeast mutants can generate sufficient energy through glycolysis, these are not lethal mutations, but provide a slow-growing 
strains to evaluate the metabolic rate and stress response. In addition to their roles in energy transformations, mitochondria are central for the synthesis of amino acids, nucleotides, and heme and Fe-S cluster proteins. Thus, such yeast strains are ideal models to assess the role of mitochondrial function in response to stress.

Petite yeast has different tolerances to chemicals, which may be related to the production of reactive oxygen species (ROS) and mitochondrial function. For example, petite yeast are more tolerant to 4-nitroquinoline 1-oxide (4NQO) than grande yeast when grown on non-fermentative carbon sources that favor respiration $[8,9]$. $4 \mathrm{NQO}$ is metabolized to the active form only in cells with functional mitochondria and petite yeast, without mitochondria and favoring fermentation, are more resistant than wild-type yeast. However, petite yeast have higher levels of endogenous ROS and are sensitive to compounds that also generate ROS [10], such as MCHM. Petite yeast are additionally more sensitive to $\mathrm{H}_{2} \mathrm{O}_{2}[10,11]$ but more resistant to copper [12]. Sod1 is the main dismutase that neutralizes ROS in the cytoplasm and the mitochondria, and mitochondrial Sod 2 also neutralizes ROS. Thus, the petite yeast-grande yeast pair represents an ideal system to evaluate the role of ROS systems, metal homeostasis, and MCHM toxicity.

The hydrophobicity of MCHM alters the membrane dynamics, which changes how cells can respond to the environment, including the import and subcellular localization of metals. Metal homeostasis is critical in that metals, such as iron $(\mathrm{Fe})$ and zinc $(\mathrm{Zn})$, play important roles in metabolism as co-factors for enzymes and other proteins, yet, if in excess, induce broad lesions to cell biology through the generation of ROS and by binding to a variety of biomolecules [13]. The coordinated activity of metal uptake and sequestration transporters function to maintain metals at optimal levels (Fig. 1). For example, there are two $\mathrm{Zn}$ transporters located on the cell membrane of yeast. Zrt1 is the high-affinity transporter that transports $\mathrm{Zn}$ when extracellular levels are low [15] and Zrt2 the low-affinity transporter [16]. Zrt3 transports Zn from storage in the vacuole to the cytoplasm when needed [17] while $\mathrm{Zrc1}$, the $\mathrm{Zn} / \mathrm{H}^{+}$antiporter, and its paralog Cot1 $[17,18]$ transport $\mathrm{Zn}$ into the vacuole from the cytoplasm. Izh1 and its paralog Izh4 are both involved in $\mathrm{Zn}$ homeostasis, by altering membrane sterol content or by directly altering cellular $\mathrm{Zn}$ levels [19, 20].

In the current study, we evaluated the impacts of MCHM on petite and grande yeast strains, focusing on metal ion homeostasis and divergent respiratory pathways in these strains as potential mechanisms of MCHM sensitivity. We integrate transcriptomics, ionomics, and QTL to identify Fe and Zn homeostasis as central to MCHM toxicity and suggest that loss of metal homeostasis underlies ROS damage and MCHM toxicity. While the MCHM has low solubility in aqueous solutions, we propose that MCHM acts as a hydrotrope, altering membrane dynamics and changing how cells responded to nutrients, including import and subcellular localization of metals via transmembrane ion transporters.

\section{Experimental Procedures}

\section{Yeast Strains and Media}

S96 petite yeast were previously generated from S96 (MATa lys5) with a 6-h incubation with ethidium bromide. The petite phenotype was validated by failure to grow on glycerol and loss of $C O X 2$ from the mitochondrial genome [9]. Yeast knockout strains were previously generated in the BY4741 background [21]. The entire coding regions of YKE4 were knocked out with hygromycin resistance marker in S96 and YJM789 [22]. S96-derived strains were grown in minimal media supplemented with lysine, while BY4741 strains grown in minimal media were supplemented with histidine, methionine, uracil, and leucine. S96 and BY4741 are considered in the S288c genetic background while YJM789 is a clinical isolate [23]. Crude MCHM was provided directly from Eastman Chemical.

\section{QTL Analysis}

Isolates of the recombinant haploid collection between S96 and YJM789 [24] were utilized to perform a QTL for MCHM tolerance. A genetic map was constructed and combined with phenotypes collected by growth curves of the segregants in YPD containing MCHM using a TECAN M200 plate reader. Briefly, cultures of segregants were grown overnight then diluted to $0.1 \mathrm{OD}_{600}$ starting concentrations in $200 \mu \mathrm{l}$ of YPD and either $0 \mathrm{ppm}(0 \mathrm{mM})$ control or 400 ppm (2.8 mM) MCHM. Each segregant was grown in biological triplicate for both control and MCHM treatments in 96-well plates. Both parent strains were grown on every plate to normalize plate-to-plate variation. Plates were grown with constant shaking and OD data was collected every $10 \mathrm{~min}$ for $24 \mathrm{~h}$. Differences in control and MCHM saturated concentrations from hours 14-19 of the growth curves were averaged into a single data point to serve as the phenotype for each segregant.

The S96 $\times$ YJM789 segregant collection used for genetic analysis contains 126 segregants genotyped at 55,958 SNPs identified by physical location. To perform the QTL analysis as previously described $[25,26]$, the genetic map was estimated for use in place of the existing physical map. Computational efficiency was also improved by collapsing the 55,958 markers into only 5076 markers. The R/QTL package based this reduction of markers on all markers that did not recombine and segregate within the population, which it collapsed into individual randomly selected markers within the 


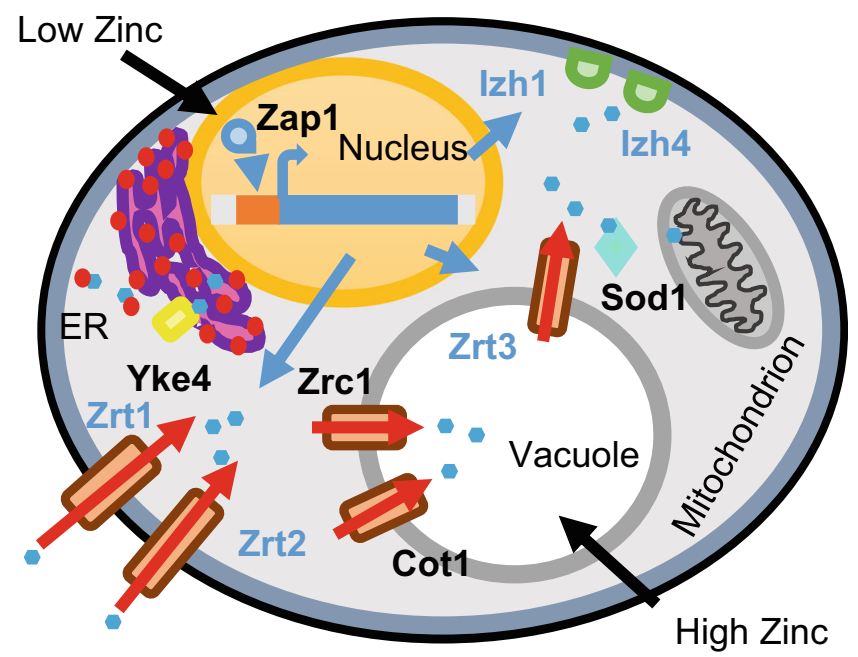

Fig. 1 Schematic of yeast cellular response to varying levels of zinc. Under low intracellular zinc levels, Zap1 induces expression of zinc uptake genes. Zrt1, the high-affinity, and Zrt2 the low-affinity transmembrane zinc transporters are localized in the cell membrane. Izh1 and Izh4 localize to the cytoplasmic side of the cell membrane and regulate zinc homeostasis. Excess zinc (blue hexagons) is stored in the vacuole and transported in by $\mathrm{Zrc1}$ and Cot1. Excess zinc stored in the

population. The genetic map was created using $\mathrm{R}$ version 3.4.3 and the QTL package version 1.41.6. A custom modification of the scripts contained in Karl W. Broman's genetic map construction guide was used to output the map, specifically utilizing known physical locations to validate that markers were ordered correctly and to identify yeast chromosome order. The qtl package was used to run the QTL analysis with the maximum likelihood EM algorithm method parameter selected to calculate LOD scores at all loci. Significance thresholds of alpha $=0.05$ were applied using 1000 permutations to determine the significance of LOD scores.

\section{Serial Dilution Assays}

Yeast were serially diluted onto solid media as previously described [25]. MCHM and $\mathrm{ZnSO}_{4}$ were added to media, autoclaved and cooled to $65^{\circ} \mathrm{C}$, which was then poured. Specific experimental conditions varying the concentrations of MCHM, zinc, and yeast strains are outlined in the results.

\section{Transcriptomics}

The RNA-seq of S96 and S96 petite yeast was carried out on hot phenol-extracted RNA [9]. The raw reads from sequencing are from 16 samples GSM2915204 through GSM2915219, including normal and petite cells. "GSE10 8873 mchm_fC1_count_table_clean.txt.gz" is the count data generated via Rsubread. "GSE108873_mchm_fC1_DESeq c2.tsv.gz" is the differential expression data generated via DESeq2. The accession number is GSE108873 (https:// www.ncbi.nlm.nih.gov/geo/query/acc.cgi?acc=GSE108873). vacuole, and when needed, Zrt3 transports zinc to the cytoplasm. In addition to the vacuole, the ribosome (red circles) bind $20 \%$ of total cellular zinc [14]. Yke4 is the transmembrane transporter at the ER (pink and purple) that transports zinc in both directions. Sod1 is the copper-zinc super oxygen dismutase that is both cytoplasmic and localizes to the inner mitochondrial membrane

GO term analysis was undertaken with clusterProfiler [27], an $\mathrm{R}$ package that implements methods to analyze and visualize functional profiles (GO and KEGG) of gene and gene clusters. For this, the ORF names from genes up- or downregulated in each condition were translated to the correspondent Entrez id using the function bitr and the package org.Sc.sgd.db. The resulting gene clusters were processed with the compareCluster function, in mode enrichGO, using org.Sc. sgd.db as database, with Biological Process ontology, cutoffs of $p$ value $=0.01$ and q value $=0.05$, adjusted by " $\mathrm{BH}$ " [28], to generate the corresponding GO profiles, which were then simplified with the function simplify. The simplified profiles were represented as dotplots, providing up to 15 most relevant categories.

\section{Elemental Analysis}

Yeast were grown to mid-log phase in YPD at which time MCHM was added to a final concentration of $550 \mathrm{ppm}$ $(3.9 \mathrm{mM})$. A total of $1.2 \times 10^{8}$ yeast cells were harvested following 0-, 10-, 30-, and 90-min exposure to MCHM. Samples were split and washed, one set twice with water and the other wash once with $10 \mathrm{mM}$ EDTA to remove metals adsorbed to the extracellular matrix. Four biological replicates for each sample were frozen in liquid nitrogen and stored at $-80{ }^{\circ} \mathrm{C}$. Cell pellets were digested in $300 \mu \mathrm{l}$ of $30 \% \mathrm{H}_{2} \mathrm{O}_{2}$ and followed by $700 \mu$ of concentrated nitric acid. Samples were heated to $85^{\circ} \mathrm{C}$ until clear. Sample volume was brought up to $10 \mathrm{ml}$ with HPLC-grade water. Digested samples were analyzed in technical triplicate by inductively coupled plasma emission spectrometry (Agilent 5110 ICP, Agilent, Santa Clara, CA, 
USA) at the following wavelengths for each metal: $\mathrm{Ca}$ 393.366, Fe 238.204, Mg 279.553, Na 589.592, P 213.618,

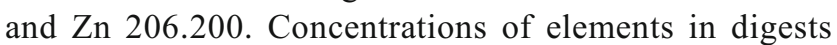
$\left(\mathrm{mg} \mathrm{l}^{-1}\right.$ ) were normalized to protein levels as determined by Bradford assay.

\section{Hydrotrope Assay}

Hydrotrope assays were carried out as previously described [29], with the following modifications. Eggs were purchased and used within 1 day. Egg whites were separated and diluted 1:6 in $50 \mathrm{mM}$ Tris- $\mathrm{HCl} \mathrm{pH} \mathrm{7.4.} \mathrm{In} \mathrm{glass} \mathrm{tubes,} 3 \mathrm{ml}$ of diluted egg whites were mixed with different concentrations of ATP, MCHM, and zinc sulfate. Samples in the glass tubes were read at $450 \mathrm{~nm}$ after $45-60 \mathrm{~s}$ of incubation at $60{ }^{\circ} \mathrm{C}$ water bath. All treatments were done in 3-4 replicates and averaged together with the standard deviation shown. Statistical differences were determined using a student $t$ test.

\section{Spheroplasting}

Spheroplasts of the BY4741 yeast strain were prepared as described [30] with the following modifications. HEPES was used as the buffer and $100 \mathrm{mg} 20 \mathrm{~T}$ zymolase was added per OD unit $\left(\mathrm{OD}_{600}\right.$ multiplied by the volume of culture); spheroplasts were incubated for $1 \mathrm{~h}$ at $30{ }^{\circ} \mathrm{C}$. In a 96-well plate, 5 replicates of each treatment were recorded: empty well, spheroplast media only, no treatment, $0.1 \%$ SDS, $0.5 \%$ sterile distilled water, $10 \mathrm{mM}$ sorbitol, $1 \mathrm{mM}$ ATP, $10 \mathrm{mM}$ $\mathrm{NaXS}, 10 \mu \mathrm{M} \mathrm{ZnSO}_{4}, 550-1000 \mathrm{ppm}$ (3.9 to $7.1 \mathrm{mM}$ ) MCHM. Using a spectrophotometer, the absorbance at $600 \mathrm{~nm}$ was recorded every for $15 \mathrm{~h}$ at room temperature.

\section{Microscopy}

Yeast with proteins tagged at the N-terminus with mCherry under the TEF2 promoter [31] were grown to log phase and then split into eight different cultures (four for treated and four for untreated). Once in log phase, samples were treated with $550 \mathrm{ppm}(3.6 \mathrm{mM}$ ) MCHM for $30 \mathrm{~min}$ followed by a 20 -min incubation time of $25 \mu \mathrm{M}$ calcofluor white (Biotium catalog number 29067) on a shaker in a dark room. Then, $30 \mu \mathrm{l}$ of each sample was placed onto a microscope slide pretreated with $40 \mu \mathrm{L}$ of $250 \mu \mathrm{g} / \mathrm{ml}$ concanavalin A via pipette and let sit under a hood for $30 \mathrm{~min}$ to dry. The coverslip was placed on top and nail polish around the edges to hold coverslip in place. Cells were imaged on Nikon A1R confocal microscope using a FITC Laser and DAPI laser. Quantitative analysis of pixel intensity to measure the change in expression of the proteins of interest after exposure to MCHM was done with Image J on 17-20 cells for each condition. The signal was normalized to untreated yeast, and statistical differences were determined using a student $t$ test.

\section{Results}

Petite yeast have different responses to chemicals because the metabolism of the yeast is shifted away from respiration. Indeed, compared to wild-type (grande) yeast, petite yeast were more sensitive to MCHM (Fig. 2). Growth inhibition of petite yeast was affected at 125 ppm MCHM while the growth of wild-type yeast was only affected at $500 \mathrm{ppm}$ MCHM. Yeast have higher tolerances to MCHM when grown in minimal media (YM); however, petite yeast grew less on YM in general (Fig. 2).

To assess the transcriptional response of petite yeast to MCHM, yeast were grown in both YPD and YM and then treated for 90 min with 550 ppm MCHM. A total of 949 genes were differentially regulated across strains and conditions (Supplemental Table 1). Gene expression levels between petite and isogenic grande yeast were similar when grown in YPD media (only six up-regulated genes: cell wall components and iron transporters, and one downregulated gene: putative mitochondrial protein, Fig. 3a), but they were clearly different when grown in YM (131 up and 117 downregulated genes, Supplemental Fig. 1A, Supplemental Table 1). In YM, petite yeast exhibited downregulated cell wall component genes, and there were also significant changes on smallmolecule metabolism-related genes (Supp. Figure 1A, 2 and 3, Supplemental. Table 1). MCHM treatment elicited the upregulation of genes involved in small molecule and sulfur compound biosynthesis, among others, in both petite and grande yeast, while the regulation of other genes differed between strains and depended on the media. For example, genes related to nucleotide and nucleoside metabolism were upregulated in the petite strain treated with MCHM only when grown in YM (Fig. 3, Supplemental Figs. 1 and 2, Supplemental Table 1). Genes downregulated due to MCHM treatment also depended on the media (Fig. 3, Supplemental Figs. 1 and 3, Supplemental Table 1). Among the genes with variable expression due to MCHM treatment and/or the use of petite vs. grande yeast were several involved in zinc homeostasis (COT1, IZH1, IZH2 and IZH4, ZRT1, and ZRT2) and iron homeostasis (ARN1 ARN2, ENB1, FIT1, FIT2, FIT3, FTR1, GGC1, and SIT1) (Fig. 3, Supplemental Fig. 1 and Supplemental Tables 2 and 3).

The increased expression of iron transporters was further explored given that mitochondria, the presence of which differs between the two strains, are the site of iron-sulfur cluster protein biogenesis. Strain ionomic profiles were evaluated for yeast strains grown in YPD. YPD was chosen to minimize the differences in growth between grande and petite yeast. Because there were differences in expression of cell wall genes such as CWP1, yeast were also washed in EDTA to determine if increased iron or other metals were associated with the cell wall (water wash) or internalized (EDTA wash). There was 


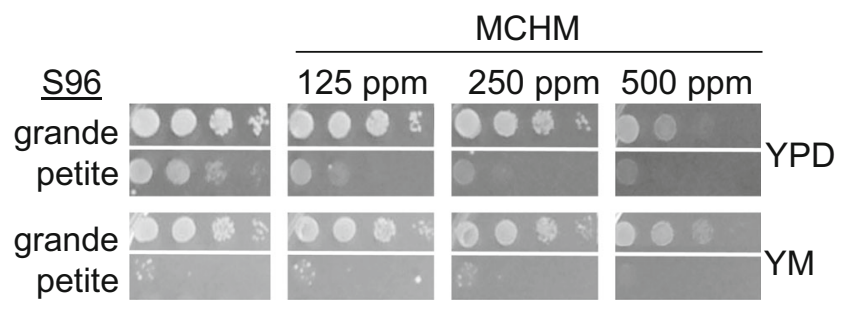

Fig. 2 Serial dilution of wild-type S96 and petite yeast in increasing concentration of MCHM in rich (YPD) and minimal (YM) media. Plates were incubated at $30^{\circ} \mathrm{C}$ for 3 days and then photographed

no difference in metal levels from yeast washed with water alone or EDTA, indicating that the levels of reported ions were absorbed into the cells and were not associated with the cell walls (Supplemental Fig. 4 and Supplemental Table 4). Iron levels were three times higher in petite yeast than grande yeast, while zinc was $60 \%$ lower in the petite strain (Fig. 4a). Other elements were typically lower in grande compared to petite yeast except for calcium (Fig. 4a, Supplemental Table 4) as yeast mitochondria do not store calcium (reviewed [32]). Levels of sodium, phosphorus, and magnesium were lower in petite yeast (Fig. 4a). Copper was below the limit of detection in this analysis.

To determine if the levels of metals in yeast were changed when exposed to MCHM, yeast were grown in YPD and then MCHM was added to a final concentration of $550 \mathrm{ppm}$. The levels of iron did not change for either grande or petite yeast over $90 \mathrm{~min}$, although the strainspecific differences noted above were still notable (Fig. $4 \mathrm{~b})$. mRNAs encoding siderophore transporters such as Arn 1 and Arn2 were expressed at higher levels, as were the Fit mannoproteins, which bind siderophores in petite yeast in YPD and MCHM compared to wild-type yeast (Supplemental Table 3). In contrast, the levels of zinc increased twofold in grande yeast but did not change in petite yeast over $90 \mathrm{~min}$ (Fig. 4c). Calcium and sodium increased with MCHM treatment in both strains with sodium increasing at a slower rate in the petite yeast (Fig. $4 \mathrm{~d}$ and e). Potassium, phosphorus, and magnesium also increased in MCHM treatment for grande, but not in petite, yeast (Fig. 4f-h). The levels of these ions are comparable to other studies [33]. After $90 \mathrm{~min}$ of MCHM
Fig. 3 Changes in RNA expression between wild type, petite grown in YPD treated with MCHM. The number of up and downregulated genes is noted on the top of each panel. a Scatter plots of $\log$ fold 2 comparisons of RNA-seq from grande (S96) and petite (S96 $\rho$ ) yeast grown in YPD. Significantly upregulated genes are labeled in red and significantly downregulated genes are labeled in blue. $\mathbf{b}$ Scatter plots of $\log$ fold 2 comparisons of RNA-seq grande yeast grown in YPD and with 550 ppm MCHM. c Scatter plots of $\log$ fold 2 comparisons of RNA-seq from petite yeast grown in YPD and with MCHM. d Scatter plots of $\log$ fold 2 comparisons of RNA-seq from S96 and S96 yeast grown in YPD and with MCHM a

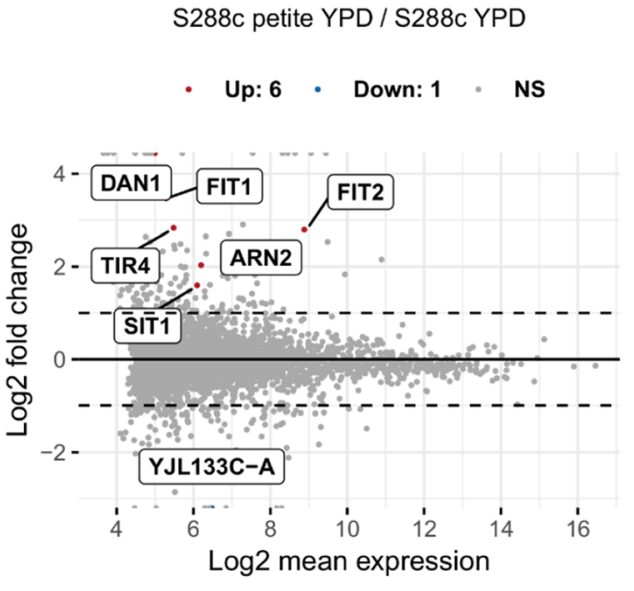

C

S288c petite YPD + MCHM / S288c petite YPD

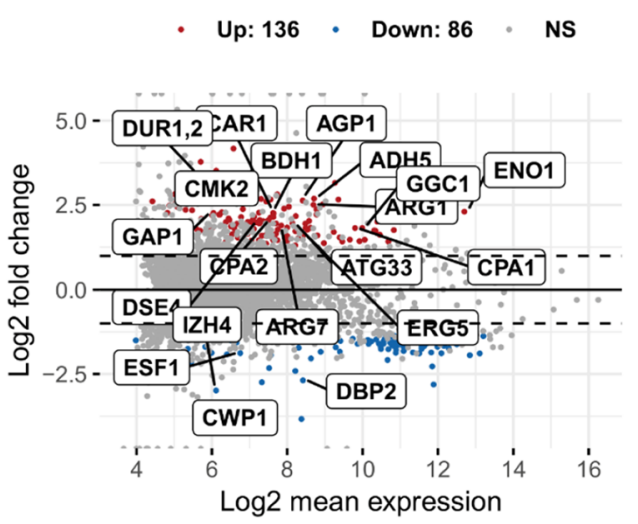

b

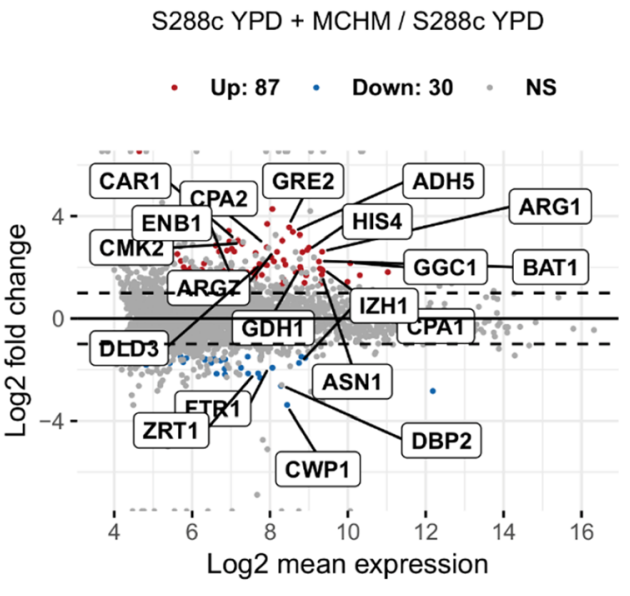

d

S288c petite YPD + MCHM / S288c YPD + MCHM

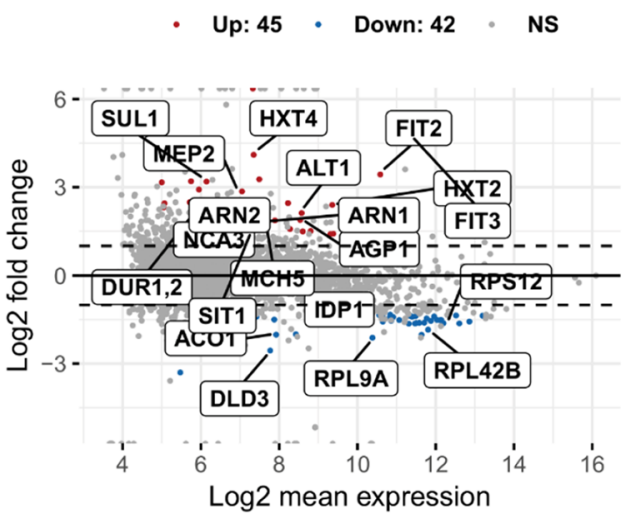


Table 1 Ionomic profiles ( $\mu \mathrm{g} / \mathrm{mg}$ protein) of wild-type (S96) and petite yeast strains were grown for $90 \mathrm{~min}$ in $\mathrm{MCHM}$

\begin{tabular}{lll}
\hline Element & Wild type & Petite \\
\hline $\mathrm{P}^{*}$ & $104.4 \pm 7.5$ & $65.8 \pm 2.2$ \\
$\mathrm{~K}^{*}$ & $19.0 \pm 0.45$ & $12.3 \pm 0.32$ \\
$\mathrm{Ca}$ & $0.554 \pm 0.048$ & $0.582 \pm 0.027$ \\
$\mathrm{Mg} *$ & $11.35 \pm 0.79$ & $7.87 \pm 0.25$ \\
$\mathrm{Na}$ & $1.64 \pm 0.13$ & $1.77 \pm 0.11$ \\
$\mathrm{Fe}^{*}$ & $0.123 \pm 0.014$ & $0.313 \pm 0.014$ \\
$\mathrm{Zn} *$ & $2.89 \pm 0.24$ & $1.17 \pm 0.04$ \\
$\mathrm{Cu}$ & $1 d$ & $\mathrm{ld}$ \\
\hline
\end{tabular}

ld level of detection

*Denotes significant differences between yeast strains $(P<0.05)$ exposure, five out of the seven ions measured was significantly higher in the grande yeast (Table 1).

There is a significant variation of growth among genetically diverse yeast strains in response to MCHM. In particular, YJM789, a yeast isolated from a human lung [23], was more sensitive than S96 at 500 ppm MCHM (Fig. 5a). Using a segregant collection of YJM789 and S96 that has been used to map genes contributing to differences in phenotypes between strains [8, 24, 25], quantitative trait loci (QTL) analysis was carried out. The growth rate in MCHM of segregant yeast strains was used to assess the association of various parts of the genome with increased growth in MCHM (Fig. 5b). Several peaks were noted, but only one broad peak on chromosome nine passed the $95 \%$ confidence threshold. Within that peak, we identified YKE4, a polymorphic ZIP family zinc transporter [34] that plays a role in zinc homeostasis by transporting zinc between the cytoplasm and
Fig. 4 Measurements of metals in yeast treated with MCHM. a Levels of $\mathrm{Fe}, \mathrm{Zn}, \mathrm{Ca}, \mathrm{Na}, \mathrm{Mg}, \mathrm{K}$ and $\mathrm{K}$ in $\mu \mathrm{g} / \mathrm{mg}$ from grande (S96) and petite (S96 $\rho$ ) yeast grown in YPD. Levels of metals from grande (S96) and petite (S96 $\rho$ ) yeast grown in YPD with $550 \mathrm{ppm}$ MCHM added for the indicated time. The ions levels measured were b Fe, $\mathbf{c} \mathrm{Zn}$, $\mathbf{d ~ C a}$, $\mathbf{e}$ $\mathrm{Na}, \mathbf{f} \mathrm{Mg}, \mathbf{g ~ K}$, and $\mathbf{h} \mathrm{F}$. The standard error is noted on the mean of four biological replicates
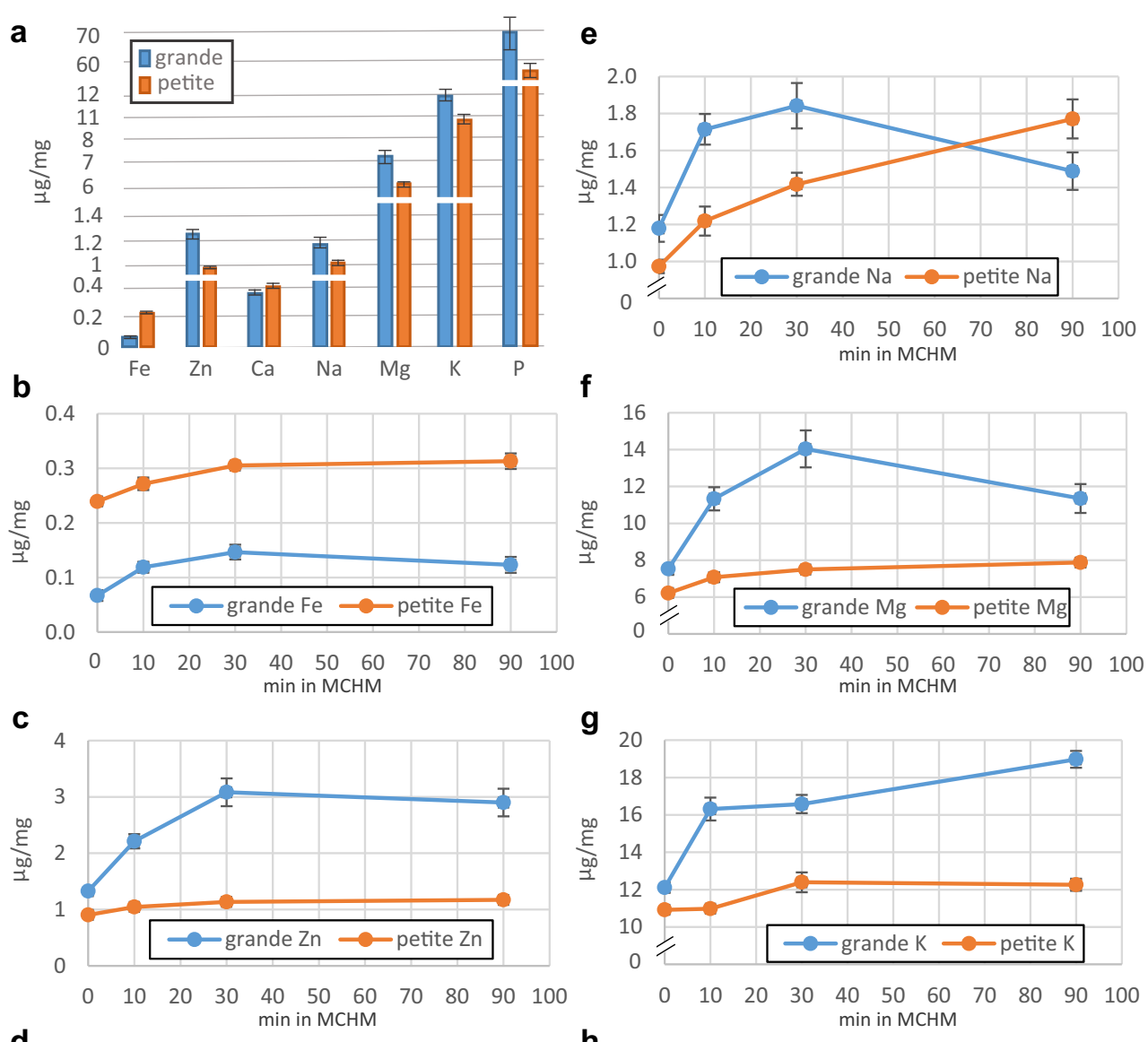

d

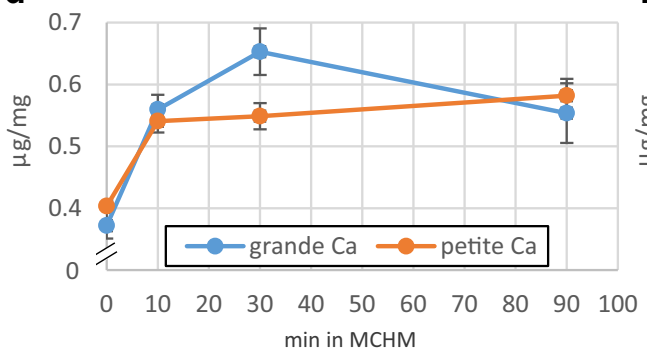

h

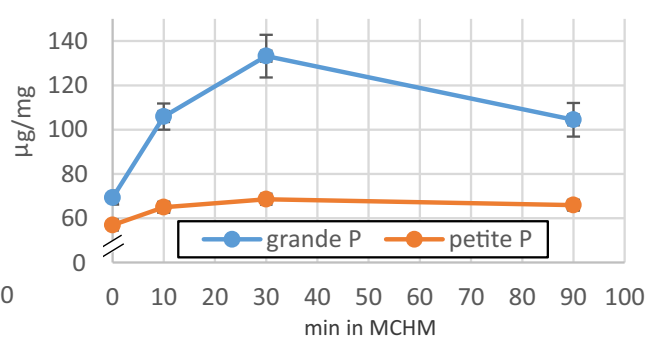




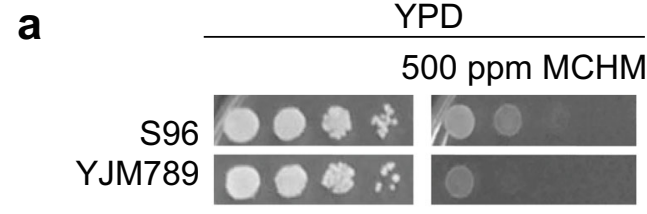

b

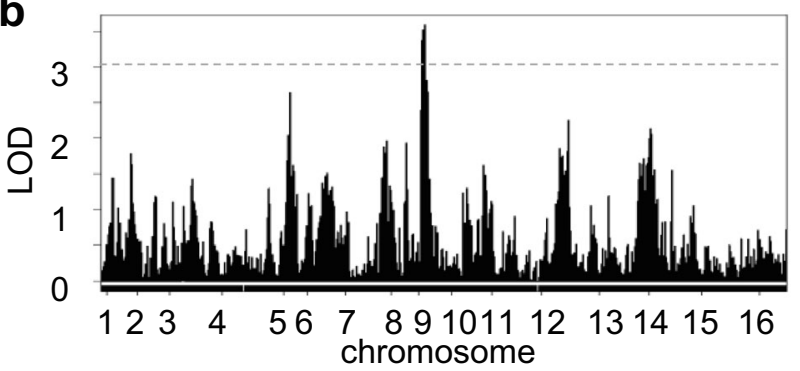

C

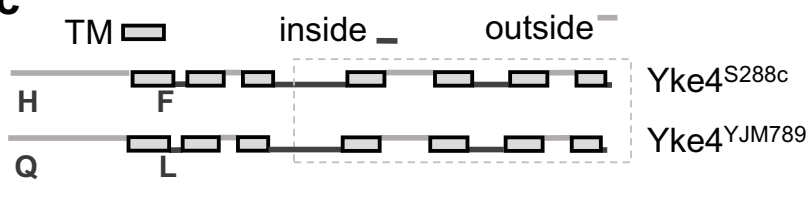

d
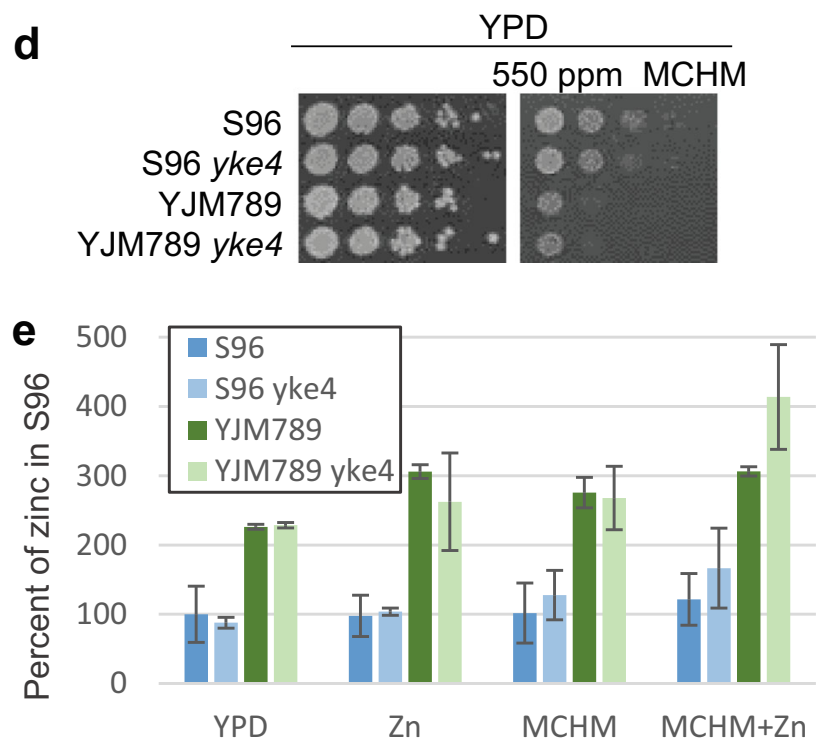

Fig. 5 Genetic variation of MCHM response linked to the YKE4 locus. a Serial dilution of genetically diverse yeast on $550 \mathrm{ppm}$ MCHM on YPD. S96 are from the S288c background and YJM789 is a clinical isolate. b Quantitative trait loci analysis of chromosomal regions linked to increased growth of yeast in MCHM from YJM789 and S96 segregants. c Diagram of Yke4 describes the transmembrane domains (TM noted with gray box) and inside or outside domains (noted with lower dark gray or upper light gray lines, respectively). Polymorphic residues are noted below in Yke4 ${ }^{\text {YJM789 }}$ compared to Yke4S288c. The conserved ZIP domain is boxed in a gray dashed line. $\mathbf{d}$ Serial dilutions of S96 and YJM789 with yke4 mutants on MCHM. e Levels of total intracellular zinc from S96, YJM789, and yke4 mutants normalized to S96 grown in YPD and total protein. Yeast were incubated with $5 \mu \mathrm{M}$ zinc sulfate, $550 \mathrm{ppm}$ MCHM, and in combination for $30 \mathrm{~min}$ before metals were extracted

the secretory pathway [34] and is localized to the ER [31]. Yke4 ${ }^{\mathrm{YJM} 789}$ contained two SNPs that change the protein's amino acid sequence (H5Q and F86L) compared to $\mathrm{Yke}^{\mathrm{S} 288 \mathrm{c}}$ (Fig. 5c). The H5Q was located in the cytoplasmic signal peptide at the N- terminus while the $\mathrm{F} 86 \mathrm{~L}$ is at the $\mathrm{C}$-terminal end of the first transmembrane domain using TMHMM [35]. To further characterize the role of Yke4, YKE4 was deleted from S96 and YJM789. Deletion of YKE4 did not alter growth in the presence of MCHM in these strains (Fig. 5d). The zinc levels were measured in these strains. The percentage of zinc was normalized to wild-type S96. Both YJM789 and the isogenic yke4 knockout strains had twice as much zinc compared to S96 (Fig. 5e). Yke4 is an ER-localized zinc transporter and plays a role in intracellular trafficking of zinc and did not appear to regulate total zinc levels. There were other genomics peaks in the QTL linked to genetic variation of MCHM response and likely contribute to differences seen between these strains.

To assess the contribution of other proteins involved in metal transport, we utilized the yeast knockout collection to determine the impact of deleting MCHM differentially regulated genes on growth. This collection is in an S96-related strain background BY4741. In contrast to S96 and YJM789 yeast, the $y k e 4$ mutant in this background was sensitive to MCHM (Fig. 6a). There were no significant changes in expression of YKE4 induced by MCHM (Supplemental Table 1). However, ARN2 expression was higher in petite yeast and, from ICP-MS analysis, the endogenous levels of iron were also higher. The BY4741 arn2 knockout was more tolerant to MCHM (Fig. 6a). The growth on MCHM of $i z h 1$ and $i z h 2$ knockouts, genes involved in zinc transport that also were differently regulated, was not altered. Iron levels did not change with the addition of MCHM (Fig. 4b). However, zinc levels increased in the wild-type grande yeast but not in the petite yeast with MCHM exposure (Fig. $4 c)$. We tested whether additional zinc could alleviate the growth inhibition by MCHM. Growth improved with the addition of $10 \mu \mathrm{M}$ of zinc sulfate in MCHM in both BY4741 and the $y k e 4$ knockout (Fig. 6b). However, at higher zinc concentrations $(100 \mu \mathrm{M})$, all growth was inhibited of all yeast when MCHM was added while zinc sulfate at this concentration alone did not alter growth (Supplemental Fig. 5A). Curiously, when zinc was added to YPD without MCHM, the media became slightly opaque. However, after several days, media cleared around yeast colonies. YPD is an undefined media composed of yeast extract, peptone, and agar. Zinc could have induced the precipitation of an unknown compound or compounds that are solubilized by the growth of yeast on solid media; the precipitation of these media components may limit yeast growth at this higher zinc concentration. Therefore, we tested whether yeast knockouts of several known zinc transporters would change the response to MCHM. First, the zinc tolerance of the $z r t 1, z r t 2, z r t 3$, and $z r c 1$ knockout yeast were tested. Only at the highest levels of zinc sulfate did the $z r c l$ mutant grow less than the other strains (Supplemental Fig. 5A). Then, the addition of $5 \mu \mathrm{M}$ of zinc sulfate completely rescued reduced growth in the presence of MCHM (Supplemental Fig. 5B). However, increasing zinc levels to $100 \mu \mathrm{M}$ further suppressed the growth of most of the yeast tested grown on 
a

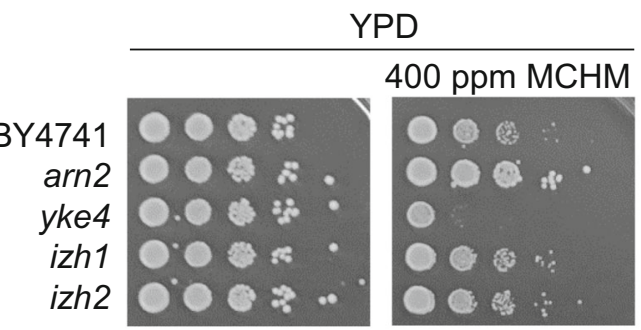

b $\quad$ YPD

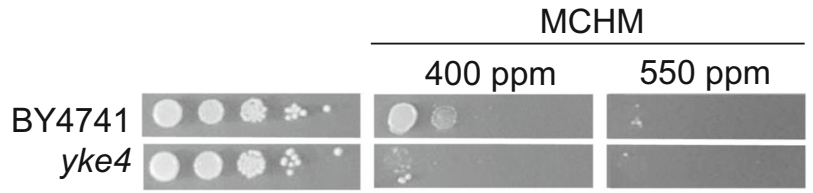

YPD $+10 \mu \mathrm{MnSO}_{4}$ $\mathrm{MCHM}$

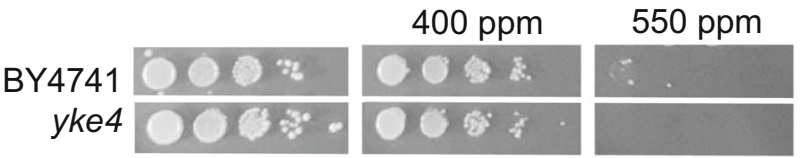

Fig. 6 Impact of loss of metal transporters on growth with MCHM and zinc-containing media. a Serial dilution of BY4741 and yeast from the knockout collection on YPD with $400 \mathrm{ppm}$ MCHM. b Serial dilution of wild-type (BY4741) and zinc transporters knocked out yeast grown in 400 or $550 \mathrm{ppm}$ MCHM on YPD with $10 \mu \mathrm{M}$ zinc sulfate

MCHM. The $z r c 1$ mutant did not grow better at $5 \mu \mathrm{M}$ and was completely inhibited at $100 \mu \mathrm{M}$ of zinc in the presence of MCHM. The suppression of growth in higher concentrations of zinc was not due to the toxicity of zinc alone as all yeast tolerated levels up to $500 \mu \mathrm{M}$ with only $z r c 1$ mutant displaying reduced growth.

MCHM is composed of a saturated hexane ring with a methyl group and a methanol group at opposite carbons (Fig. 7a). The methanol and methyl group can be in the cis or trans conformation. These characteristics of MCHM allow it to act as a hydrotrope, a compound that can solubilize hydrophobic substances in aqueous environments. We thus considered MCHM's role in altering protein-membrane and protein-protein interactions, which may explain the impacts of MCHM on the transcriptome and ionome. In vitro protein aggregation was carried out with sodium xylene sulfate (NaXS), an industrial hydrotrope; ATP, a biologically relevant hydrotrope [29]. and MCHM. Compared to no treatment (aggregation was set at $100 \%$ for no treatment at $45 \mathrm{~s}$ ), NaXS reduced aggregation to $48 \%$ ( $p=0.0064)$, ATP reduced aggregation to $3 \%(p=0.00025)$, and $550 \mathrm{ppm}$ MCHM treatment reduced aggregation to $60 \%(p=0.02)$. However, at $1 \mathrm{~min}$ of incubation, MCHM allowed full protein aggregation and was not distinguishable from untreated controls $(p=28)$, while $\mathrm{NaXS}$ and ATP continued to prevent protein aggregation (Fig. 7b). Levels of zinc sulfate that rescued MCHMinduced growth inhibition increased aggregation by $60 \%$
(Fig. 7b). Zinc sulfate on its own caused nearly immediate aggregation of protein which was not prevented by the addition of MCHM. We tested if adding MCHM before zinc changed the rate of aggregation. When MCHM was added first followed by zinc sulfate, protein aggregation showed no difference at $45 \mathrm{~s}$ but was at the highest of all treatments tested at $1 \mathrm{~min}$ of incubation.

Yeast have cell walls that protect cells from osmotic stress, and the cell wall can be easily removed to produce spheroplasts. However, unlike plants and fission yeast, spheroplasted yeast continue to divide their nuclei but do not undergo cytokinesis [36-38] leading to large multinucleated yeast. In this way, we can determine if hydrotropes can cause yeast to lyse when the cell wall is not providing rigid support. SDS, a commonly used detergent, reduced the optical density as yeast cells lysed. Sorbitol provides osmotic support and did not affect yeast growth (Fig. 7c). Treatment of spheroplast with known hydrotropes (ATP and $\mathrm{NaXS}$ ) did not alter the growth of spheroplasted yeast over $15 \mathrm{~h}$ while the growth of spheroplasts treated with MCHM was arrested but did not cause lysis (Fig. 7c). The dose-dependent reduction of spheroplasted growth likely mirrors the growth inhibition on plates with MCHM. The growth arrest is reversible in $\mathrm{MCHM}$, as cells will continue growing after MCHM is removed (data not shown). The subcellular localization of Zrt1, Zrt2, Zrt3, and Yke4 was measured as cells were exposed to MCHM. Proteins were tagged at the N-terminus with mCherry [31], and cells were stained with calcofluor white to highlight the cell wall. Fluorescence of each protein remained diffused and no foci appeared after $90 \mathrm{~min}$ of exposure (Supplemental Fig. 6A). The endogenous promotors were replaced with a common constitutive promoter (TEF2) so any increased expression of Zrt1, Zrt2, and Yke4 would likely be at the protein level rather than the mRNA level when exposed to MCHM. The protein levels of the Zrt transporters in YPD change by no more than $20 \%$ under the TEF2 promoter while Yke4 levels were fourfold higher than Yke4 under its endogenous promoter [31]. When treated with MCHM, protein levels of Zrt1, Zrt2, and Yke4 increased modestly while Zrt3 levels decreased, (Supplemental Figure 6B). Levels of ZRT1 and ZRT2 mRNAs were decreased with MCHM (Supplemental Table 2).

\section{Discussion}

The loss of the mitochondrial DNA and treatment with MCHM had pleiotropic effects on yeast. Petite yeast responded to stresses, including MCHM, differently than grande yeast. From RNA-seq analysis, iron and zinc transporters were differentially regulated in petite yeast and grande yeast in response to MCHM. In petite yeast, levels of zinc were lower while iron levels were higher. Transcriptomics pointed to metal transporters while genetic analysis uncovered genetic variation in Yke4, an internal zinc transporter as 
a

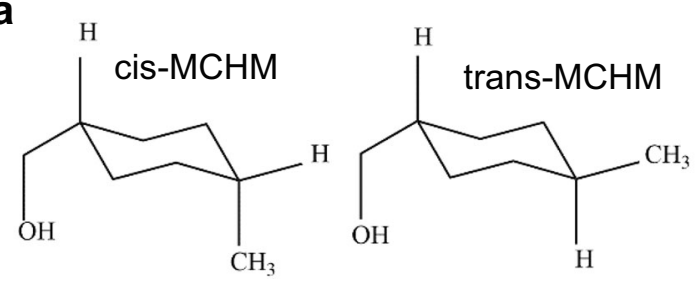

C

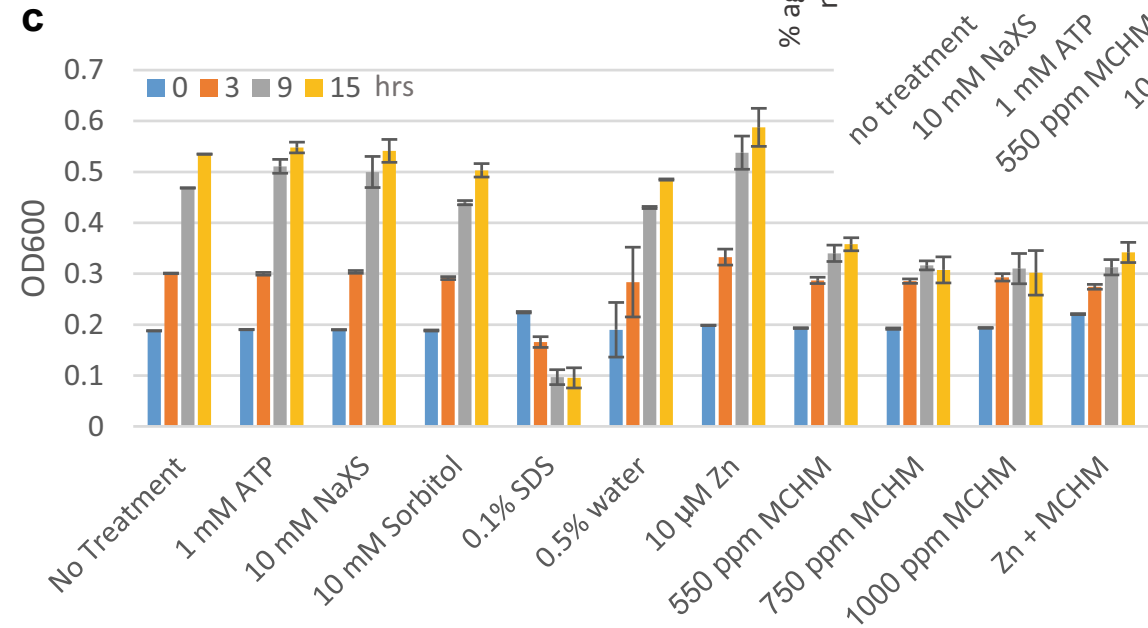

b

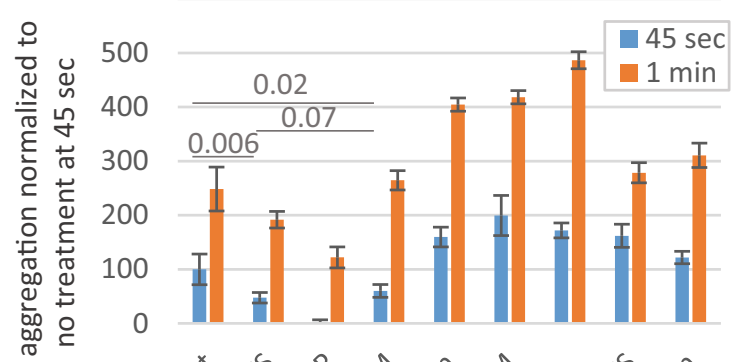

Fig. 7 MCHM role in protein aggregation. a Chemical structure of the cis and trans conformation of MCHM. b Timed protein aggregation when exposed to heat. No treatment is compared to $10 \mathrm{mM}$ sodium xylene sulfate, $1 \mathrm{mM}$ ATP, and $550 \mathrm{ppm}$ MCHM. The optical density of samples was measured at $450 \mathrm{~nm}$ after incubation at $60{ }^{\circ} \mathrm{C} .550 \mathrm{ppm}$ MCHM was added to samples then $10 \mu \mathrm{M}$ zinc sulfate was added where indicated. $\mathbf{c}$ Spheroplast yeast were incubated for between 0 and $15 \mathrm{~h}$ with $0.1 \%$ SDS, $0.5 \%$ water, $10 \mathrm{mM}$ sorbitol, $1 \mathrm{mM}$ ATP, $10 \mathrm{mM}$ $\mathrm{NaXS}, 10 \mu \mathrm{M}$ zinc sulfate and 550-1000 ppm MCHM, and samples were read at $600 \mathrm{~nm}$. Biological quadruplicates were averaged and standard error. Relevant $p$ values were calculated using the student $t$ test important to MCHM. On non-fermentable carbon sources, yke4 mutants do not grow in the presence of excess zinc [34], further highlighting that internal zinc transport yeast differed in many other ways. To address how MCHM could affect the wide range of biochemical pathways seen, MCHM was tested and shown to be a hydrotrope in vitro, which could exert cell wall or membrane stress.

Petite yeast grew slower and were especially sensitive to the growth inhibition of MCHM. This may be in part due to the altered ionome of petite yeast. This includes higher levels of iron from increased expression of iron transporters and lower endogenous zinc levels. These petite yeast were induced by loss of the mitochondrial genome and petite yeast caused by other types of mutations also had differences in internal metals and regulation in the iron regulome [39]. There is an interplay between metal levels, as zinc transporters are also important for responding to high levels of copper [25]. Zrt1 protein levels increase in response to high levels of copper [25] and in contrast to the mRNA, Zrt1 under the control of a generic promoter and 5'UTR increased protein expressed by $66 \%$ in MCHM treatment. While genetic variation in Zrt2 contributes to copper tolerance [25], Zrt2 protein levels also increased by $26 \%$ with MCHM exposure. Supplementation with zinc alleviates copper-induced growth inhibition as well as MCHM growth inhibition.

The levels of sodium, calcium, phosphate, and magnesium also increased, suggesting drastic changes at the cell wall and membrane in response to MCHM. Although mRNAs of the iron acquisition pathway were increased in MCHM treatment, there was only a modest change in iron levels. Other stresses, such as starvation induced by rapamycin, also induce the iron regulon [40]. Deletion of arn2 improved growth. Arn2 is localized to the ER and suggests a role in subcellular localization of iron in the yeast [31]. MCHM-treated yeast are not starved for iron as GTL1 and GDH3 expression was not altered. These Gtll and Gdh3 are iron-dependent enzymes that are downregulated in iron-limiting media and upregulated in iron-replete media [41]. The addition of zinc rescued growth of yeast on MCHM at low levels of zinc $(5-10 \mu \mathrm{M})$, while levels above $100-500 \mu \mathrm{M}$ in combination with MCHM drastically reduced growth. Therefore, it appears that the metals have an optimum level to ameliorate the effects of MCHM. Based on RNA-seq and QTL analysis, two transporters of zinc were identified as having an important role in MCHM response. We found no correlation between levels of internal zinc and poor growth on MCHM, possibly because 
subcellular localization of zinc was critical to growth, rather than absolute levels of the metal. There could also be a period of adjustment that could not be captured due to the differences in time points between measuring metal levels and growth. Metal levels were measured at $30 \mathrm{~min}$ of exposure while growth was measured after 2 days. YKE4 expression levels between YJM789 and S96 are not different in unperturbed cells [42], and there are no SNPs in the $5^{\prime}$ UTR or $3^{\prime}$ UTR [43], suggesting that the polymorphisms in Yke4 itself contributed MCHM sensitivity in addition to other genetic differences. While BY4741 yke4 was MCHM sensitive, deletion in S288c and YJM789 had no effect. There are hundreds of genetic differences between BY4741 and S288c and thousands in YJM789 $[44,45]$. The pleiotropic effects of MCHM on yeast combined with the many smaller yet not quite statistically significant peaks in the QTL point to $\mathrm{MCHM}$ resistance as a polygenic trait likely spread throughout the genome. Other yeast strains have the H5Q polymorphism and a subset of those also have the F86L polymorphism. To separate the role of transcription and 5'UTR dependent, the promoter and 5'UTR of YKE4 was replaced. With MCHM treatment, Yke4 zinc levels increased 20\%. A total of 582 proteins are predicted to bind zinc with 20 proteins binding $90 \%$ of total cellular zinc [14], and zinc sparing ensures that essential $\mathrm{Zn}$ binding proteins have zinc. As YJM789 expresses less Zrt1 protein normally [25], perhaps the internal levels of zinc and the ability of the yeast to quickly redistribute the zinc in MCHM may alter their ability to grow.

Hydrotropes in cells prevent protein aggregation, but unlike surfactants, work at millimolar concentrations and display low cooperativity. In addition to changes in protein levels, post-translational modifications, and subcellular location, changes in protein conformation also regulate protein function. Protein aggregation is generally thought to inactivate proteins. Protein aggregation includes prions, which increase phenotypic plasticity without changing genetic diversity [46]. Intrinsically disordered regions of protein can separate proteins without being membrane-bound which is an important step in RNA granule formation [47]. Transmembrane domain proteins such as Zrts, Yke4, and Arn transporters have multiple extracellular and intracellular loops that would be also disordered regions. MCHM slowed the aggregation of proteins in an in vitro assay, and with zinc sulfate, that induced protein aggregation appeared to increase the rate of aggregation rather than preventing it. MCHM showed similar hydrotrope activity to NaXS, an industrial hydrotrope, but it was not as potent as ATP. Transcriptomics carried out after $90 \mathrm{~min}$, approximately one generation in yeast, detected changes in mRNA encoding metal transporters. Zinc is required for both the syntheses of cell walls and phospholipids $[34,48]$. Exposure of yeast to MCHM increased intracellular sodium levels, yet yeast do not actively accumulate sodium [49], further supporting that MCHM alters the protein structures to either increase the bioavailability of ions or transport across cell membranes. MCHM altered the levels of ions in the cell at the earliest time points. Therefore, we conclude that this is likely through altered protein conformation at the cell membrane of many proteins because of the diverse metals that changed during MCHM exposure. Proteins and organelles are increasingly found in altered conformations to change local concentrations of proteins in (reviewed [50]). Inside the cell, MCHM could alter how molecules interact in liquid droplet changing the function of protein functions and metabolites in the cell.

Acknowledgments This work was supported by a grant from the NIH (R15ES026811-01A1) to JEGG and the USDA (1007681R) to JRC and JEGG. WVU Imaging Facilities and the Nikon A1R/N SIM-E are supported by the following grants U54GM104942 and P20GM103434. We are indebted to Wallace Marshall for the insightful suggestions of MCHM as a hydrotrope. Xiaoqing Rong-Mullins assisted in uploading the RNAseq reads to the public database. Maya Schuldiner from the Weizmann Institute shared the mCherry SWAp-TAG collection. Angela Lee from Stanford University shared the yeast knockout collection. The content is solely the responsibility of the authors and does not necessarily represent the official views of the National Institutes of Health. Preprint of this paper was uploaded to BioRxiv on June 7, 2019 [51].

Author Contributions JEGG designed the experiments and wrote the manuscript. AP carried out RNA-seq analysis. ZNS measured mCherrytagged proteins, tested protein aggregation and with RJV and MCA carried out yeast growth assays. MCA carried out QTL analysis and constructed strains. JRC analyzed results from ICP and assisted in writing.

\section{Compliance with Ethical Standards}

Conflict of Interest The authors declare that they have no conflicts of interest.

Open Access This article is distributed under the terms of the Creative Commons Attribution 4.0 International License (http:// creativecommons.org/licenses/by/4.0/), which permits unrestricted use, distribution, and reproduction in any medium, provided you give appropriate credit to the original author(s) and the source, provide a link to the Creative Commons license, and indicate if changes were made.

\section{References}

1. Maugh TI (1983) How many chemicals are there? Science 220(80):293

2. Guerrero PF (1994) Toxic Substances Control Act: EPA's limited progress in regulating toxic chemicals. http://archive.gao.gov/ t2pbat3/151661.pdf

3. Lan J, Hu M, Gao C, et al (2015) Toxicity assessment of 4-methyl1-cyclohexanemethanol and its metabolites in response to a recent chemical spill in West Virginia, USA. Environ Sci Technol,

4. Tullo AH, Kemsley J, Hogue C, Morrissey SR (2014) Obscure chemical taints water supply. Chem Eng News 92:10-15

5. Hsu J, del Rosario MC, Thomasson E, Bixler D, Haddy L, Duncan MA (2017) Hospital impact after a chemical spill that compromised the potable water supply: West Virginia, January 2014. Disaster 
Med Public Health Prep 11:621-624. https://doi.org/10.1017/dmp. 2016.193

6. Cui D, Mebel AM, Arroyo-Mora LE, Holness H, Furton KG, O'Shea K (2017) Kinetic, product, and computational studies of the ultrasonic induced degradation of 4-methylcyclohex anemethanol (MCHM). Water Res 126:164-171. https://doi.org/ 10.1016/j.watres.2017.09.005

7. Weidhaas JL, Dietrich AM, DeYonker NJ et al (2016) Enabling science support for better decision-making when responding to chemical spills. J Environ Qual 45:1490. https://doi.org/10.2134/ jeq2016.03.0090

8. Gallagher JEG, Zheng W, Rong X, Miranda N, Lin Z, Dunn B, Zhao H, Snyder MP (2014) Divergence in a master variator generates distinct phenotypes and transcriptional responses. Genes Dev 28:409-421

9. Rong-Mullins XX, Ayers MC, Summers M, Gallagher JEG (2018) Transcriptional profiling of Saccharomyces cerevisiae reveals the impact of variation of a single transcription factor on differential gene expression in $4 \mathrm{NQO}$, fermentable, and nonfermentable carbon sources. G3 Genes, Genomes, Genet 8. https://doi.org/10.1534/g3. 117.300138

10. Grant CM, MacIver FH, Dawes IW (1997) Mitochondrial function is required for resistance to oxidative stress in the yeast Saccharomyces cerevisiae. FEBS Lett 410:219-222. https://doi. org/10.1016/S0014-5793(97)00592-9

11. Thorpe GW, Fong CS, Alic N, Higgins VJ, Dawes IW (2004) Cells have distinct mechanisms to maintain protection against different reactive oxygen species: oxidative-stress-response genes. Proc Natl Acad Sci U S A 101:6564-6569. https://doi.org/10.1073/pnas. 0305888101

12. Liang Q, Zhou B (2007) Copper and manganese induce yeast apoptosis via different pathways. Mol Biol Cell 18:4741-4749. https:// doi.org/10.1091/mbc.E07-05-0431

13. Himelblau E, Mira H, Lin SJ, Cizewski Culotta V, Peñarrubia L, Amasino RM (1998) Identification of a functional homolog of the yeast copper homeostasis gene ATX1 from Arabidopsis. Plant Physiol 117:1227-1234

14. Wang Y, Weisenhorn E, MacDiarmid CW et al (2018) The cellular economy of the Saccharomyces cerevisiae zinc proteome. Metallomics 10:1755-1776. https://doi.org/10.1039/C8MT00269J

15. Zhao H, Eide D (1996) The yeast ZRT1 gene encodes the zinc transporter protein of a high-affinity uptake system induced by zinc limitation. Proc Natl Acad Sci 93:2454-2458

16. Lyons TJ, Gasch AP, Gaither LA, Botstein D, Brown PO, Eide DJ (2000) Genome-wide characterization of the Zap 1p zinc-responsive regulon in yeast. Proc Natl Acad Sci U S A 97:7957-7962 https:// doi.org/97/14/7957 [pii]

17. MacDiarmid CW, Gaither LA, Eide D (2000) Zinc transporters that regulate vacuolar zinc storage in Saccharomyces cerevisiae. EMBO J 19:2845-2855. https://doi.org/10.1093/emboj/19.12.2845

18. Conklin DS, McMaster JA, Culbertson MR, Kung C (1992) COT1, a gene involved in cobalt accumulation in Saccharomyces cerevisiae. Mol Cell Biol 12:3678-3688. https://doi.org/10.1128/ MCB.12.9.3678

19. Lyons TJ, Villa NY, Regalla LM, Kupchak BR, Vagstad A, Eide DJ (2004) Metalloregulation of yeast membrane steroid receptor homologs. Proc Natl Acad Sci U S A 101:5506-5511. https://doi.org/ 10.1073/pnas.0306324101

20. Byrne KP, Wolfe KH (2005) The yeast gene order browser: combining curated homology and syntenic context reveals gene fate in polyploid species. Genome Res 15:1456-1461. https://doi.org/10. 1101/gr.3672305

21. Giaever G, Chu AM, Ni L, Connelly C, Riles L, Véronneau S, Dow S, Lucau-Danila A, Anderson K, André B, Arkin AP, Astromoff A, el Bakkoury M, Bangham R, Benito R, Brachat S, Campanaro S, Curtiss M, Davis K, Deutschbauer A, Entian KD, Flaherty P, Foury
F, Garfinkel DJ, Gerstein M, Gotte D, Güldener U, Hegemann JH, Hempel S, Herman Z, Jaramillo DF, Kelly DE, Kelly SL, Kötter P, LaBonte D, Lamb DC, Lan N, Liang H, Liao H, Liu L, Luo C, Lussier M, Mao R, Menard P, Ooi SL, Revuelta JL, Roberts CJ, Rose M, Ross-Macdonald P, Scherens B, Schimmack G, Shafer B, Shoemaker DD, Sookhai-Mahadeo S, Storms RK, Strathern JN, Valle G, Voet M, Volckaert G, Wang CY, Ward TR, Wilhelmy J, Winzeler EA, Yang Y, Yen G, Youngman E, Yu K, Bussey H, Boeke JD, Snyder M, Philippsen P, Davis RW, Johnston M (2002) Functional profiling of the Saccharomyces cerevisiae genome. Nature 418:387-391

22. Goldstein AL, McCusker JH (1999) Three new dominant drug resistance cassettes for gene disruption in Saccharomyces cerevisiae. Yeast 15:1541-1553

23. McCusker JH, Clemons KV, Stevens DA, Davis RW (1994) Genetic characterization of pathogenic Saccharomyces cerevisiae isolates. Genetics 136:1261-1269

24. Steinmetz LM, Sinha H, Richards DR, Spiegelman JI, Oefner PJ, McCusker JH, Davis RW (2002) Dissecting the architecture of a quantitative trait locus in yeast. Nature 416:326-330

25. Rong-Mullins X, Winans MJ, Lee JB, Lonergan ZR, Pilolli VA, Weatherly LM, Carmenzind TW, Jiang L, Cumming JR, Oporto GS, Gallagher JEG (2017) Proteomic and genetic analysis of S. cerevisiae response to soluble copper leads to improvement of antimicrobial function of cellulosic copper nanoparticles. Metallomics 9:1304-1315. https://doi.org/10.1039/C7MT00147A

26. Rong-Mullins X, Ravishankar A, McNeal KA et al (2017) Genetic variation in Dip5, an amino acid permease, and Pdr5, a multiple drug transporter, regulates glyphosate resistance in $\mathrm{S}$. cerevisiae. PLoS One 12:e187522. https://doi.org/10.1371/journal.pone. 0187522

27. Yu G, Wang L-G, Han Y, He Q-Y (2012) clusterProfiler: an R package for comparing biological themes among gene clusters. Omi A J Integr Biol 16:284-287. https://doi.org/10.1089/omi. 2011.0118

28. Benjamini Y, Hochberg Y (1995) Controlling the false discovery rate: a practical and powerful approach to multiple testing. J R Stat Soc Ser B 57:289-300. https://doi.org/10.1111/j.2517-6161.1995. tb02031.x

29. Patel A, Malinovska L, Saha S et al (2017) ATP as a biological hydrotrope. Science 356(80):753-756. https://doi.org/10.1126/ science.aaf6846

30. Katzmann DJ, Wendland B (2005) Analysis of ubiquitin-dependent protein sorting within the endocytic pathway in Saccharomyces cerevisiae. Methods Enzymol 399:192-211. https://doi.org/10. 1016/S0076-6879(05)99013-7

31. Weill U, Yofe I, Sass E, Stynen B, Davidi D, Natarajan J, BenMenachem R, Avihou Z, Goldman O, Harpaz N, Chuartzman S, Kniazev K, Knoblach B, Laborenz J, Boos F, Kowarzyk J, Ben-Dor S, Zalckvar E, Herrmann JM, Rachubinski RA, Pines O, Rapaport D, Michnick SW, Levy ED, Schuldiner M (2018) Genome-wide SWAp-tag yeast libraries for proteome exploration. Nat Methods 15:617-622. https://doi.org/10.1038/s41592-018-0044-9

32. Cyert MS, Philpott CC (2013) Regulation of cation balance in Saccharomyces cerevisiae. Genetics 193:677-713

33. Eide DJ, Clark S, Nair TM, Gehl M, Gribskov M, Guerinot M, Harper JF (2005) Characterization of the yeast ionome: a genome-wide analysis of nutrient mineral and trace element homeostasis in Saccharomyces cerevisiae. Genome Biol 6:R77. https:// doi.org/10.1186/gb-2005-6-9-r77

34. Kumánovics A, Poruk KE, Osborn KA, Ward DM, Kaplan J (2006) YKE4 (YIL023C) encodes a bidirectional zinc transporter in the endoplasmic reticulum of Saccharomyces cerevisiae. J Biol Chem 281:22566-22574. https://doi.org/10.1074/jbc.M604730200

35. Krogh A, Rn Larsson BÈ, Von Heijne G, Sonnhammer ELL (2001) Predicting transmembrane protein topology with a hidden Markov 
model: application to complete genomes. J Mol Biol 305:567-580. https://doi.org/10.1006/jmbi.2000.4315

36. Komiyama T, Kimura T, Furuichi Y (2002) Round shape enlargement of the yeast spheroplast of Saccharomyces cerevisiae by HM1 toxin. Biol Pharm Bull 25:959-965

37. Fukudomi T, Kotani T, Miyakawa I (2011) A simple method for culture and stable maintenance of giant spheroplasts from the yeast Saccharomyces cerevisiae. J Gen Appl Microbiol 57:177-182

38. Kelly FD, Nurse P (2011) De novo growth zone formation from fission yeast spheroplasts. PLoS One 6:e27977. https://doi.org/10. 1371/journal.pone.0027977

39. Xue Y, Schmollinger S, Attar N, Campos OA, Vogelauer M, Carey MF, Merchant SS, Kurdistani SK (2017) Endoplasmic reticulummitochondria junction is required for iron homeostasis. J Biol Chem 292:13197-13204. https://doi.org/10.1074/jbc.M117.784249

40. Preiss T, Baron-Benhamou J, Ansorge W, Hentze MW (2003) Homodirectional changes in transcriptome composition and mRNA translation induced by rapamycin and heat shock. Nat Struct Mol Biol 10:1039-1047. https://doi.org/10.1038/nsb1015

41. Shakoury-Elizeh M, Tiedeman J, Rashford J, Ferea T, Demeter J, Garcia E, Rolfes R, Brown PO, Botstein D, Philpott CC (2004) Transcriptional remodeling in response to iron deprivation in Saccharomyces cerevisiae. Mol Biol Cell 15:1233-1243. https:// doi.org/10.1091/mbc.e03-09-0642

42. Zheng W, Zhao H, Mancera E, Steinmetz LM, Snyder M (2010) Genetic analysis of variation in transcription factor binding in yeast. Nature 464:1187-1191

43. Xu Z, Wei W, Gagneur J, Perocchi F, Clauder-Münster S, Camblong J, Guffanti E, Stutz F, Huber W, Steinmetz LM (2009) Bidirectional promoters generate pervasive transcription in yeast. Nature 457:1033-1037

44. Song G, Dickins BJ, Demeter J et al (2015) AGAPE (automated genome analysis pipeline) for pan-genome analysis of Saccharomyces cerevisiae. PLoS One 10:e120671. https://doi. org/10.1371/journal.pone.0120671
45. Wei W, McCusker JH, Hyman RW et al (2007) Genome sequencing and comparative analysis of Saccharomyces cerevisiae strain YJM789. Proc Natl Acad Sci U S A 104:12825-12830. https:// doi.org/10.1073/pnas.0701291104

46. Snell-Rood EC, Van Dyken JD, Cruickshank T et al (2010) Toward a population genetic framework of developmental evolution: the costs, limits, and consequences of phenotypic plasticity. Bioessays 32:71-81

47. Lin Y, Protter DSW, Rosen MK, Parker R (2015) Formation and maturation of phase-separated liquid droplets by RNA-binding proteins. Mol Cell 60:208-219. https://doi.org/10.1016/j.molcel.2015. 08.018

48. Iwanyshyn WM, Han G-S, Carman GM (2004) Regulation of phospholipid synthesis in Saccharomyces cerevisiae by zinc. J Biol Chem 279:21976-21983. https://doi.org/10.1074/jbc.M402047200

49. Haro R, Rodríguez-Navarro A (2002) Molecular analysis of the mechanism of potassium uptake through the TRK1 transporter of Saccharomyces cerevisiae. Biochim Biophys Acta Biomembr 1564:114-122. https://doi.org/10.1016/S0005-2736(02)00408-X

50. Boeynaems S, Alberti S, Fawzi NL, Mittag T, Polymenidou M, Rousseau F, Schymkowitz J, Shorter J, Wolozin B, van den Bosch L, Tompa P, Fuxreiter M (2018) Protein phase separation: a new phase in cell biology. Trends Cell Biol 28:420-435. https:// doi.org/10.1016/J.TCB.2018.02.004

51. Pupo A, Ayers MC, Sherman ZN et al (2019) MCHM acts as a hydrotrope, altering the balance of metals in yeast. bioRxiv:606426. https://doi.org/10.1101/606426

Publisher's Note Springer Nature remains neutral with regard to jurisdictional claims in published maps and institutional affiliations. 